\title{
Serratia marcescens, a Phloem-Colonizing, Squash Bug-Transmitted Bacterium: Causal Agent of Cucurbit Yellow Vine Disease
}

\author{
B. D. Bruton, United States Department of Agriculture-Agricultural Research Service (USDA-ARS), Lane, OK \\ 74555; F. Mitchell, Texas Agricultural Experiment Station, Stephenville 76401; J. Fletcher, Department of \\ Entomology and Plant Pathology, Oklahoma State University, Stillwater 74078; S. D. Pair, USDA-ARS, Lane, OK; \\ A. Wayadande, Department of Entomology and Plant Pathology, Oklahoma State University; U. Melcher, Depart- \\ ment of Biochemistry and Molecular Biology, Oklahoma State University; J. Brady, Texas Agricultural Experiment \\ Station; B. Bextine, Department of Entomology and Plant Pathology, Oklahoma State University; and T. W. \\ Popham, USDA-ARS, Stillwater, OK 74075
}

\begin{abstract}
Bruton, B. D., Mitchell, F., Fletcher, J., Pair, S. D., Wayadande, A., Melcher, U., Brady, J., Bextine, B., and Popham, T. W. 2003. Serratia marcescens, a phloem-colonizing, squash bugtransmitted bacterium: Causal agent of cucurbit yellow vine disease. Plant Dis. 87:937-944.

Cucurbit yellow vine disease (CYVD), which can inflict heavy losses to watermelon, pumpkin, cantaloupe, and squash in U.S. production areas from the midwest to northeastern states, causes phloem discoloration, foliar yellowing, wilting, and plant decline. Bacteria were cultured from the phloem of crown sections of symptomatic plants of Citrullus lanatas and Cucurbita pepo. Those bacteria testing positive in CYVD-specific polymerase chain reaction (PCR) were all gram negative and appeared morphologically identical, producing creamy white, smooth, entire, convex colonies on Luria-Bertani or nutrient agar. Characterized cucurbit-derived strains of Serratia marcescens were introduced into greenhouse-grown squash plants by puncture inoculation and into field-grown squash plants by enclosure with $S$. marcescens-fed squash bugs, Anasa tristis. Up to $60 \%$ of the bacteria-inoculated plants in the greenhouse and up to $17 \%$ of field plants caged with inoculative squash bugs developed phloem discoloration and tested positive for S. marcescens by CYVD-specific PCR. None of the controls developed phloem discoloration or tested positive by PCR. Of the diseased field plants, 12\% (2 of 35) also yellowed, wilted, and collapsed, exhibiting full symptom development of CYVD. However, neither plant collapse nor decline was observed in the greenhouse-grown, puncture-inoculated plants. The morphology, growth habit, and PCR reaction of bacteria cultured from crown tissue of a subset of plants in each experimental group were indistinguishable from those of the inoculum bacteria. Evidence presented from our studies confirms that the squash bug can transmit $S$. marcescens, the CYVD causal bacterium. The S. marcescens-A. tristis relationship described here is the first instance in which the squash bug has been identified as a vector of a plant pathogen. Our experiments represent a completion of the steps of Koch's postulates, demonstrating that $S$. marcescens is the causal agent of CYVD and that the squash bug, $A$. tristis, is a vector of the pathogen.
\end{abstract}

Additional keywords: Coreidae, Heteroptera, vine decline

Cucurbit yellow vine disease (CYVD) was first observed in squash and pumpkin (Cucurbita spp.) in 1988 in Oklahoma and Texas (9). In 1991, the disease was observed in watermelon (Citrullus lanatas (Thunb.) Matsum. \& Nakai) fields near Rush Springs and Terral, OK, and DeLeon and Gustine, TX (10). CYVD has been observed in squash, pumpkin, or watermelon in Tennessee (5), Massachusetts (34), and Arkansas (J. C. Correll, personal

Corresponding author: B. D. Bruton

E-mail: bbruton-usda@lane-ag.org

Accepted for publication 26 March 2003.

Publication no. D-2003-0527-02R

This article is in the public domain and not copyrightable. It may be freely reprinted with customary crediting of the source. The American Phytopathological Society, 2003. communication). Losses can range from less than 5 to $100 \%$ in affected fields of watermelon, squash, pumpkin, and cantaloupe (Cucumis melo var. cantaloupensis Naudin). Diseased plants usually exhibit stunting, yellowing, and gradual decline beginning about 10 to 14 days prior to harvest. Occasionally, a rapid wilt occurs at the time of flowering or fruit set and plants collapse within a single day without the associated plant yellowing (7). The symptom most diagnostic and consistent with the disease in all four plant species is a honeybrown discoloration of the phloem (7). Disease symptoms consistently have been associated with the presence of a walled bacterium, observed by electron microscopy in phloem sieve tubes (7). Sequence analysis of a genomic DNA fragment amplified by CYVD-specific primers from such plants indicated that this microbe was closely related to Serratia marcescens (1).
Early studies provided evidence that the disease was likely insect transmitted (8). For example, CYVD-symptomatic watermelon plants often were aggregated in small patches (12) and weekly insecticide applications significantly reduced the incidence of CYVD (8). In watermelon and cantaloupe fields of 5 ha or more, the incidence of CYVD was generally greater in perimeter rows than in the middle of the field. Bextine et al. (2) demonstrated that CYVD could be prevented in squash field plots by using mesh row-cover fabric to exclude insects. Several insect species initially were tested as potential vectors, although these preliminary studies failed to positively confirm or exclude any particular insect (25). Empirical evidence continued to implicate the squash bug Anasa tristis (DeGeer) as a vector of CYVD. Historically, although it never has been reported as a pathogen vector, the squash bug has been a serious pest of cucurbits, particularly squash and pumpkin. Its pest status and biology are reviewed elsewhere (21). In contrast to previous reports, squash bugs also can be an extremely serious pest of watermelon in Oklahoma and Central Texas $(13,23,24,28)$, an area subject to severe outbreaks of CYVD (7). Pair et al. (26) reported that a small percentage of squash plants exhibited phloem discoloration characteristic of CYVD after being confined with squash bugs that previously had been caged on diseased plants.

The overall goals of the present research were to complete the steps of Koch's postulates, to partially characterize the CYVD pathogen, and to investigate the means by which the pathogen is disseminated. In this paper we report: (i) cultivation of a walled bacterium consistently associated with CYVD symptoms, (ii) identification of one insect vector of CYVD, (iii) development of a plant inoculation technique that yields acceptable infection rates, and (iv) reproduction of CYVD disease symptoms following inoculation. Preliminary reports, in the form of abstracts, have been published $(2,6)$.

\section{MATERIALS AND METHODS}

Bacterial isolation and maintenance. In July 1999, a symptomatic watermelon 
plant was collected at the Texas Agricultural Experiment Station at Stephenville, TX. Small wedges $(\approx 0.1 \mathrm{~g})$ from the phloem, excised from the hypocotyls of symptomatic plants that tested positive for CYVD by polymerase chain reaction (PCR) assay (described below), were placed in a $1.5-\mathrm{ml}$ tube and ground in 0.5 $\mathrm{ml}$ of potassium phosphate buffer (PBS), $\mathrm{pH}$ 7.2. The suspension was streaked onto purple agar (Difco Laboratories, Detroit) plates and incubated at $37^{\circ} \mathrm{C}$. After $24 \mathrm{~h}$, bacteria picked from colonies of varying morphology and pigmentation were subjected to DNA extraction and PCR. Bacteria from PCR-positive colonies were suspended in PBS, pH 7.4, diluted 1:1000, plated on purple agar, and retested by PCR to confirm their identity. A similar study was initiated at Stillwater, OK, using a symptomatic squash plant. In studies reported elsewhere, the bacteria reacting positively in the CYVD-specific PCR were identified by sequence analysis of their $16 \mathrm{~S}$ and groE gene sequences (27) and repetitive sequence-based polymerase chain reaction (rep-PCR) and DNA-DNA hybridization (35) as Serratia marcescens. Each plant isolate was single-cell cloned three times to assure genotypic homogeneity and frozen in $20 \%$ glycerol at $-80^{\circ} \mathrm{C}$. Subsequent routine cultivation was on LuriaBertani (LB) agar or broth, or in nutrient agar. Reference strains were designated as WO1-A isolated from watermelon and ZO1-A isolated from zucchini squash. In a

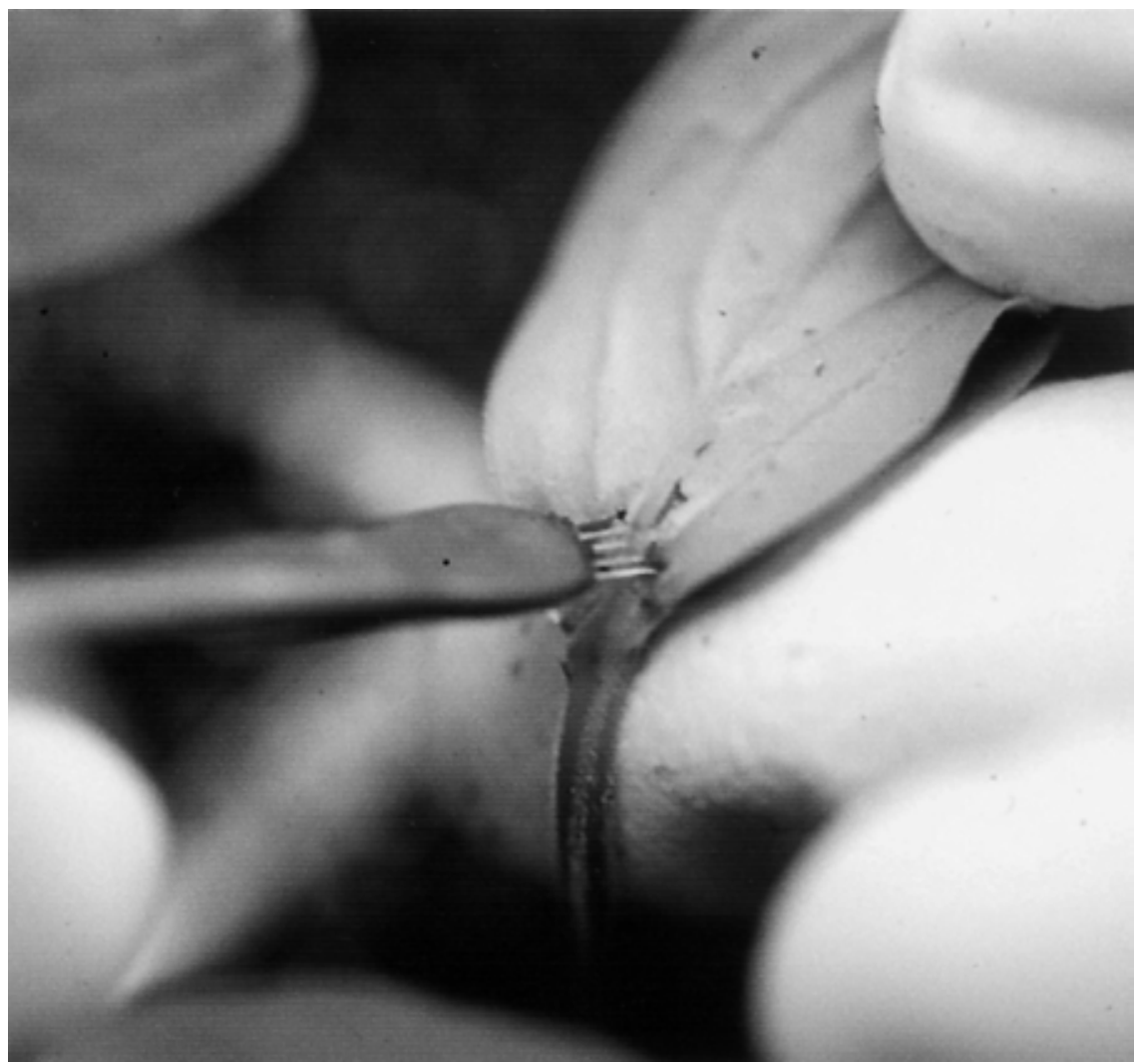

Fig. 1. Illustration of puncture-inoculation of squash seedling at the stem-cotyledon junction with test bacteria.

subsequent study, a total of 47 symptomatic plants (phloem discoloration, plant yellowing, and vine decline) from cucurbit production areas in Texas and Oklahoma were isolated in a similar fashion as previously described. These included $34 C$. lanatas, 5 C. melo, and 8 Cucurbita pepo, and a similar number of asymptomatic plants.

PCR was used to trace or locate bacterial colonies amplified by primers YV1 (5'GGG AC TTG CTC CCC GG-3') and YV4 (5'-AAC GTC AAT TGA TGA ACG TAT TAA GT-3') as described by Avila et al. (1) and modified by Melcher et al. (20) A sample was considered positive if a single band of $0.4 \mathrm{kbp}$ in size was present.

Plant inoculation. Seed of yellow squash (cv. Lemon Drop) were planted in 128-cell trays (Speedling Inc., Sun City, FL) filled with Redi-Earth soil-less mix (Scotts Sierra Horticultural Products Co., Marysville, $\mathrm{OH}$ ) and maintained in a growth chamber at $30^{\circ} \mathrm{C}$ or in the greenhouse at 22 to $35^{\circ} \mathrm{C}$. Bacteria were grown for 3 to 5 days on nutrient agar (NA) and suspended in PBS. Bacterial CFU were estimated by spectrophotometry (PerkinElmer, Norwalk, CT) at $420 \mathrm{~nm}$, comparing absorbance to a previously calibrated bacterial dilution series. To determine the optimum bacterial concentration for inoculation, titers of $1 \times 10^{6}, 1 \times 10^{8}, 1 \times$ $10^{9}$, and $1 \times 10^{10} \mathrm{CFU} / \mathrm{ml}$ were tested. Duplicate studies of 20 replications each were inoculated with each bacterial

938 Plant Disease / Vol. 87 No. 8 concentration. Bacterial strains W01-A and Z01-A were used as inoculum, and an equal number of plants were inoculated with PBS as controls. Plants were inoculated at the expanded cotyledon stage, using a vascular puncture method adapted from that of Louie (17). Specifically, both cotyledons were pressed together between thumb and forefinger and bent to an angle of about $45^{\circ}$. Approximately $20 \mu \mathrm{l}$ of bacterial suspension was pipetted onto the stem at the junction of the stem and cotyledon. Beginning at the site of inoculum deposition (Fig. 1), six to eight penetrations were made with an inoculating fork obtained from R. Louie and M. G. Redinbaugh. The instrument was tipped with five stainless steel insect minuten pins (Bioquip, Gardena, CA) each $0.15 \mathrm{~mm}$ in diameter, of equal length, and spaced $0.4 \mathrm{~mm}$ apart. The pins penetrated through the cotyledon, the apical meristem, and into the cotyledon on the other side. At 3 to 4 days after inoculation, seedlings were transplanted, one per pot, into black plastic pots $(15 \mathrm{~cm}$ in diameter by $17 \mathrm{~cm}$ in height) containing sterilized sand, placed in the greenhouse $\left(22\right.$ to $\left.35^{\circ} \mathrm{C}\right)$, and fertilized weekly with $0.3 \%$ Peter's Solution 20-20-20 (Spectrum Group, St. Louis, $\mathrm{MO})$. At 28 days after inoculation, the plants were uprooted, the roots were rinsed with tap water, and a thin hand-cut crosssection was taken at the root-stem junction. A cross-section of each test plant was observed by light microscopy for the presence or absence of phloem discoloration. An adjoining 5-mm section was subjected to DNA extraction and PCR to confirm that only symptomatic plants were PCR positive. Isolations were made from representative plants from all treatments between the second and third internode to determine if the bacterium had moved beyond the point of inoculation. The percentage of plants with CYVD as determined by phloem discoloration and PCR was regressed over bacterial concentration for each isolate. Covariance analysis was used to determine if data from different experiments could be combined for one regression.

To standardize the puncture-inoculation procedure and determine the optimum plant growth stage for artificial inoculation, squash plants (cv. Lemon Drop) were inoculated at the closed or nonexpanded cotyledon stage (5 days after planting [DAP]), expanded cotyledon stage (7 DAP), first true leaf stage (11 DAP), or second true leaf stage (14 DAP) (Fig. 2). The relation between growth stage and DAP is dependent on temperature. Consequently, DAP are not constant and are used here for ease of data presentation. Seed of yellow squash were planted in 128 cell Speedling trays filled with Redi-Earth soilless mix. Temperatures in the greenhouse during seed germination ranged from 22 to $36^{\circ} \mathrm{C}$. Plants were inoculated with strains 
WO1-A or ZO1-A at $1 \times 10^{11} \mathrm{CFU} / \mathrm{ml}$ as previously described, transplanted to plastic pots, and maintained in the greenhouse. The study was duplicated with 20 replications/treatment/study. At 28 days after inoculation, the plants were evaluated for phloem discoloration and subjected to DNA extraction and PCR as previously noted. Isolations were made from five plants from each treatment. For the study on effect of plant growth stage on infection rate, the number of plants exhibiting phloem discoloration was analyzed using likelihood ratio tests to evaluate the effect of strain, number of DAP, and the interaction of strain and DAP. In each experiment, the percentage of plants with phloem discoloration was regressed over DAP using the model $Y=a+b X^{\mathrm{c}}$, where $Y$ is the percentage of plants with phloem discoloration and $X$ is the number of DAP. Likelihood ratio tests and covariance analysis at $P \leq 0.05$ determined statistical significance.

Host range. A host range study of the two reference strains of $S$. marcescens, WO1-A and ZO1-A, was made by artificial inoculation of watermelon (cv. Royal Sweet), cantaloupe (cv. Hymark), pumpkin (cv. Connecticut Field), and cucumber (cv. Marketmore 76) in addition to squash (cv. Lemon Drop). Seed were planted in Speedling trays in a growth chamber $\left(30^{\circ} \mathrm{C}\right)$ or in the greenhouse $\left(22\right.$ to $\left.35^{\circ} \mathrm{C}\right)$. Puncture inoculations were made to seedlings at the expanded cotyledon stage as described for the previous study, using $S$. marcescens W01-A or Z01-A at $1 \times 10^{10}$ $\mathrm{CFU} / \mathrm{ml}$. Inoculated seedlings were transplanted to plastic pots and maintained in the greenhouse. At 28 days after inoculation, plants were sampled and evaluated for phloem discoloration and subjected to DNA extraction and PCR as previously noted. Duplicate studies were conducted with 20 replications/treatment in addition to a control for each study. For the limited host range study, the number of symptomatic responses (phloem discoloration) was analyzed using likelihood ratio tests (Proc GenMod, SAS 2000, SAS Institute Inc., Cary, NC) to evaluate effects of cucurbit crops, strains, and cucurbit cropstrain interaction. The percentage of positive responses was calculated for each cucurbit species and strain in each of the three experiments and used to compute the mean percent and standard error for each strain and cucurbit crop.

Because we used a high concentration of bacterial inoculum $\left(1 \times 10^{10} \mathrm{CFU} / \mathrm{ml}\right)$ to achieve meaningful infection rates, we tested whether bacteria other than the cucurbit strains of $S$. marcescens were capable of causing CYVD symptoms in inoculated squash plants. Five bacteria (Table 1) shown by $S$. marcescens-specific PCR or fatty acid methyl ester (FAME) (E. Dickstein, University of Florida) to differ from $S$. marcescens were used for inoculation.
The bacteria were isolated from field-collected squash bugs, buffalo gourd, pumpkin, or watermelon, and puncture inoculated at $1 \times 10^{10} \mathrm{CFU} / \mathrm{ml}$ into Lemon Drop squash seedlings at the expanded cotyledon stage. In addition, $S$. marcescens W01-A and ZO1-A, or buffer, were included as positive and negative controls, respec-
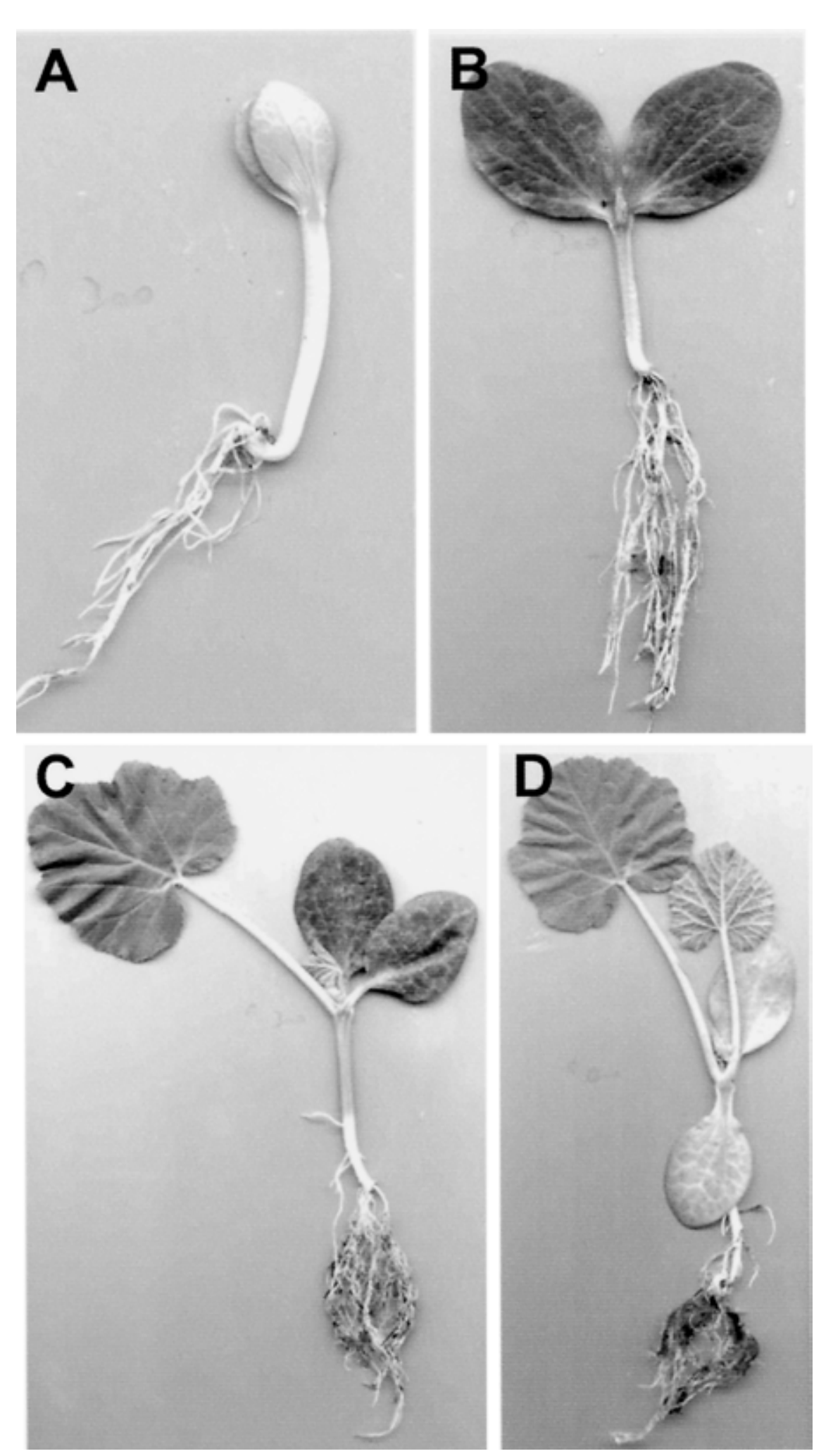

Fig. 2. Illustration of developmental growth stage (days after planting [DAP]) of squash at which inoculations were made; A, closed or nonexpanded cotyledon stage (5 DAP), B, expanded cotyledon stage (7 DAP), C, first true-leaf stage (11 DAP), and D, third true-leaf stage (14 DAP).

tively. Plants were treated as described previously for symptom development and PCR. Five studies were executed, with 15 replications/treatment in each study.

Acquisition of $S$. marcescens by $A$. tristis. A. tristis (obtained from J. Edelson, Oklahoma State University) individuals were maintained in colony on pumpkin . 
plants and squash fruit in mesh-covered cages at a 14-h light, 10-h dark photoperiod at room temperature. Insects acquired $S$. marcescens using an artificial feeding system developed specifically for squash bugs (2). A volume of $20 \mathrm{ml}$ of a log phase culture of ZO1-A, diluted with sterile d$\mathrm{H}_{2} \mathrm{O}$ to $1 \times 10^{5} \mathrm{CFU} / \mathrm{ml}$, or $20 \mathrm{ml}$ of $\mathrm{LB}$ broth, diluted similarly, as a control treatment, was placed in a 1-liter Erlenmeyer flask with a vacuum port. Twenty $6-\mathrm{mm}^{3}$ cubes of squash fruit cortex tissue were added and a vacuum was applied. When air bubbles (air escaping from intercellular spaces) appeared, the vacuum was released, forcing the bacterial suspension to infiltrate into the intercellular spaces. The vacuum process was repeated three times. A squash bug feeding apparatus was constructed by resting a $6-\mathrm{cm}^{2}$ square of rigid nylon mesh (1-mm $\mathrm{mm}^{2}$ openings) on the rim of the bottom half of a 6 -cm-diameter petri dish. An infiltrated squash cube was placed on top of the mesh grid. Adult squash bugs,

Table 1. Characteristics of bacterial isolates used to inoculate squash (Cucurbita pepo) cv. Lemon Drop

\begin{tabular}{|c|c|c|c|c|}
\hline Isolate ID & Host or origin & $\begin{array}{l}\text { Gram } \\
+ \text { or - }\end{array}$ & $\begin{array}{c}\text { PCR } \\
\text { YV primers } 1 / 4^{\mathrm{a}}\end{array}$ & Bacterial identification \\
\hline W01-A & Watermelon & - & Positive & Serratia marcescens $s^{\mathrm{b}}$ \\
\hline Z01-A & Zucchini squash & - & Positive & S. marcescens ${ }^{\mathrm{b}}$ \\
\hline 00B075 & Squash bug & - & Negative & Burkholderia cepacia ${ }^{\mathrm{c}}$ \\
\hline 00B025 & Buffalo gourd & + & Negative & Agrobacterium rubi ${ }^{\mathrm{c}}$ \\
\hline 01B081 & Squash bug & - & Negative & B. glathe $^{\mathrm{c}}$ \\
\hline 00B053 & Pumpkin & - & Negative & Entrobacter hormaechei \\
\hline 00B052 & Watermelon & - & Negative & E. cancerogenus ${ }^{\mathrm{c}}$ \\
\hline
\end{tabular}

a Polymerase chain reaction (PCR) results with respect to Serratia marcescens based on primers of Melcher et al. (21). Positive $=$ amplification of $0.4 \mathrm{kbp}$ and negative $=$ no amplification .

${ }^{\mathrm{b}}$ Identified as $S$. marcescens by sequence analysis of $16 \mathrm{~S}$ and $g r o E$ gene (28) and rep-PCR and DNA-DNA hybridization (36).

${ }^{\mathrm{c}}$ Identification based on fatty acid methyl ester best fit (E. Dickstein, University of Florida).

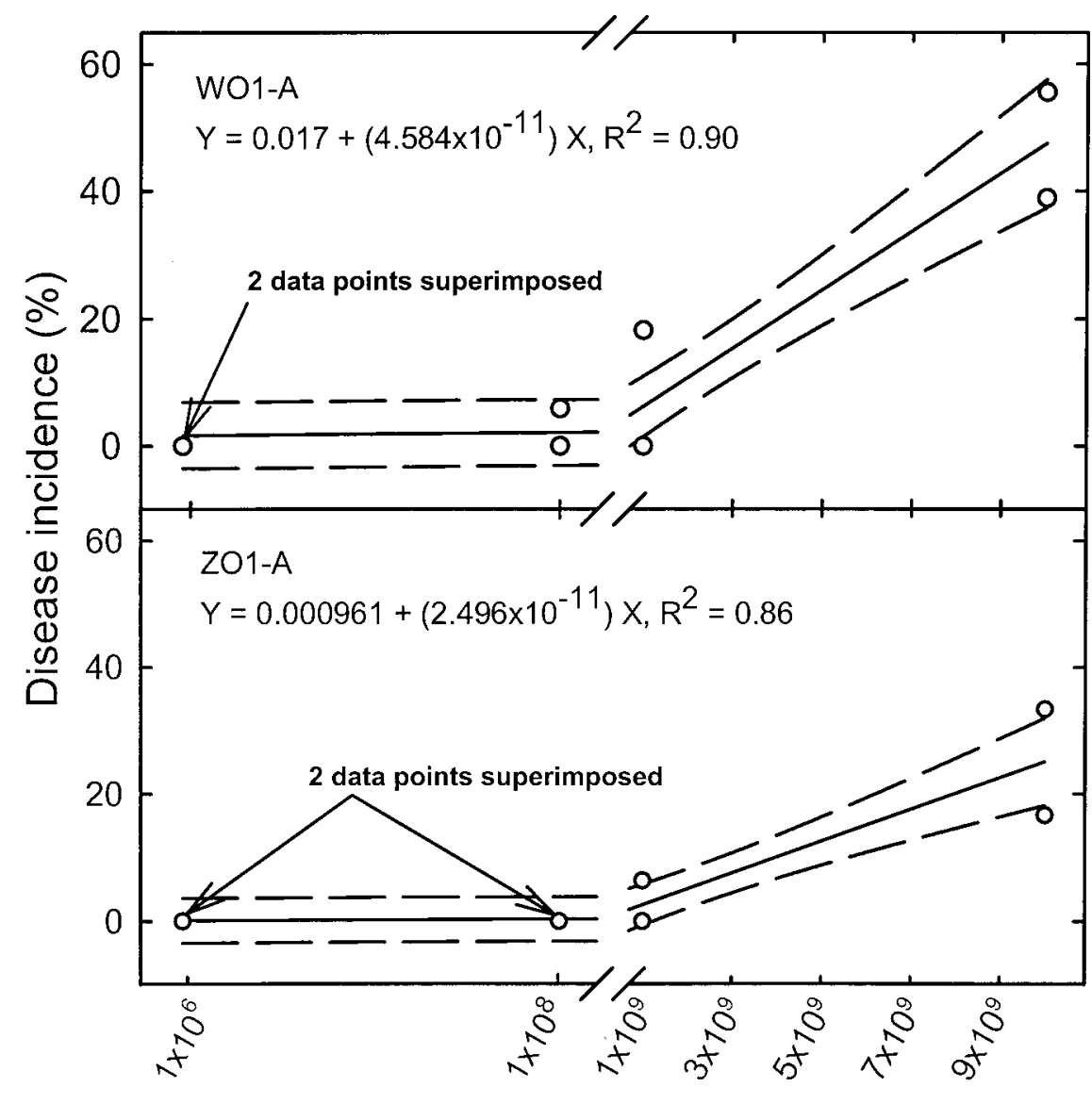

Bacterial inoculum concentration

Fig. 3. Effect of bacterial inoculum concentration on the development of cucurbit yellow vine disease symptoms in squash (cv. Lemon Drop). Plants inoculated at first true-leaf stage (11 days after planting) using puncture inoculation. Dotted lines represent the standard error of the mean. Data points represent the means of 23 observations. confined in the dish below the grid, were forced to feed on the squash cube by probing through the grid from below, preventing fecal contamination of the cubes. The acquisition access period was $48 \mathrm{~h}$.

Squash bug inoculations of field plants. Squash seed, cv. Lemon Drop, were planted 4 August 2000 at $25-\mathrm{cm}$ intervals in four $30-\mathrm{m}$ rows, $1.9 \mathrm{~m}$ apart, at the Oklahoma State University Plant Pathology Farm, Stillwater. Soaker hose was deployed along the length of each row and plants were irrigated as needed. Using a completely randomized design, three 6-m sections in each row were totally enclosed in Reemay ( 1.70 by $27 \mathrm{~m}, 15.6 \mathrm{~g} / \mathrm{m}^{2}$; Reemay Inc., Old Hickory, TN), a mesh row cover fabric, supported by 9-gauge metal hoops embedded in the ground. The enclosures were sealed by spreading soil over the fabric edges. After plants had reached the four-leaf stage, squash bugs, totaling one per plant, were released at an even distribution within the Reemay enclosures. Treatments consisted of squash bugs fed on squash cubes infiltrated with $S$. marcescens, squash bugs fed on squash cubes infiltrated with LB broth without $S$. marcescens, and no squash bugs. There were four replications/treatment. Insects remained on the plants for the duration of the experiment. In all, 120 squash plants at random sites throughout the plot were left uncovered to assess the natural incidence of CYVD. At the time of flowering, 2 to 3 hymenopteran pollinators (families Halictidae and Andrenidae), collected by sweeping vegetation in and around the cucurbit plot, were introduced to all enclosures to ensure pollination and fruit set. Plants were observed weekly for CYVD symptom expression. One study was conducted during the late summer of 2000.

Field plants developing symptoms of plant yellowing and some degree of stunting following exposure to $S$. marcescensfed squash bugs were removed from enclosures and checked visually for phloem discoloration and by PCR for the presence of the bacterium. At the end of the experiment, all plants, whether symptomatic or not, were tested for phloem discoloration and assayed by PCR as noted previously. Bacteria cultured from selected PCR-positive plants were indistinguishable by $16 \mathrm{~S}$ rDNA sequencing (data not presented) from the ZO1-A strain that had been inoculated.

\section{RESULTS}

Bacterial isolation. Bacteria cultivated from a symptomatic watermelon sample had various morphologies and pigmentation. Colonies that tested positive by CYVD-specific PCR were dilution-plated and single colonies were picked for a total of three times to assure population homogeneity and establish that bacterial growth had occurred. Those colonies testing positive by CYVD-specific PCR were 
all indistinguishable, round, smooth, entire, convex, and creamy white in color, with a colony size of approximately 1.5 to 2.0 mm after 4 days of growth at $28^{\circ} \mathrm{C}$ on NA. Although the CYVD bacterium generally dominated the culture, the relatively slow growth allowed other, more active colonies to engulf the plate. Cells were gram negative and rod shaped. Bacteria from colonies, dispersed in a drop of buffer on a microscope slide and examined at $\times 40$, appeared nonmotile. The same procedure was used to isolate the bacterium from a symptomatic squash plant with similar results.

In a subsequent study, isolations were made from 47 CYVD symptomatic cucurbits exhibiting phloem discoloration. $S$. marcescens was isolated from 32 of 34 (94\%) Citrullus lanatas, 5 of 5 (100\%) Cucumis melo, and 7 of 8 (88\%) Cucurbita pepo. In contrast, $S$. marcescens was not isolated from a similar number of asymptomatic plants.

Mechanical plant inoculation. Using $S$. marcescens strains WO1-A and ZO1-A, the concentration of the bacterial inoculum was highly correlated $\left(R^{2}=0.79\right)$ with percentage of disease development in puncture-inoculated squash, ranging from $0.0 \%$ at $1 \times 10^{6} \mathrm{CFU} / \mathrm{ml}$ to nearly $50 \%$ at 1 $\times 10^{10} \mathrm{CFU} / \mathrm{ml}$ (Fig. 3). Less than $10 \%$ of plants exhibited phloem discoloration when inoculated at $1 \times 10^{8}$ using the WO1A strain. Both strains incited disease symptoms (phloem discoloration) at $1 \times$ $10^{9} \mathrm{CFU}$. Based on disease development, the watermelon strain WO1-A had a higher infection rate $(\mathrm{P} \leq 0.05)$ in squash than the zucchini strain, ZO1-A. Symptoms exhibited by test plants included stunting (Fig. 4), slight yellowing, and phloem discoloration, all symptoms associated with CYVD. All symptomatic and none of the inoculated, but asymptomatic, plants were PCR positive for the CYVD bacterium. The bacteria were reisolated from symptomatic CYVD squash stem tissue collected between the second and third node, tissue that was not yet formed at time of inoculation.

Percentage of infection of squash plants was highly dependent on the growth stage (DAP) at which they were inoculated. Approximately $60 \%$ of the plants developed symptoms (phloem discoloration, stunting, and plant yellowing) of CYVD when they were inoculated at the nonexpanded cotyledon stage (Fig. 5). Percentage of infection decreased almost $50 \%$ when seedlings were inoculated at the expanded cotyledon stage. Only about $10 \%$ of the plants developed symptoms of CYVD when inoculated at the first true leaf stage. Symptoms consisted of plant yellowing, stunting, and phloem discoloration and bacteria were isolated from only these plants.

Host range. Of the plant species tested, squash and pumpkin exhibited the highest percentage of CYVD infection following puncture inoculation with WO1-A or ZO1-
A (Fig. 6). There was a significant interaction between strain and crop with respect to CYVD incidence in the cucurbits tested. Percentage of plants that exhibited symptoms of CYVD in watermelon, cucumber, and cantaloupe averaged less than $10 \%$. Infection of cantaloupe was observed in only one of three experiments in which WO1-A was used as inoculum, and none of

the cantaloupe plants inoculated with strain ZO1-A developed symptoms.

When non-Serratia bacteria were inoculated at a high inoculum concentration to test for their ability to cause CYVD-like symptoms in squash, none of the test plants exhibited any symptom at the inoculation site or within the phloem 28 days later. In addition, none of the plants inoculated with

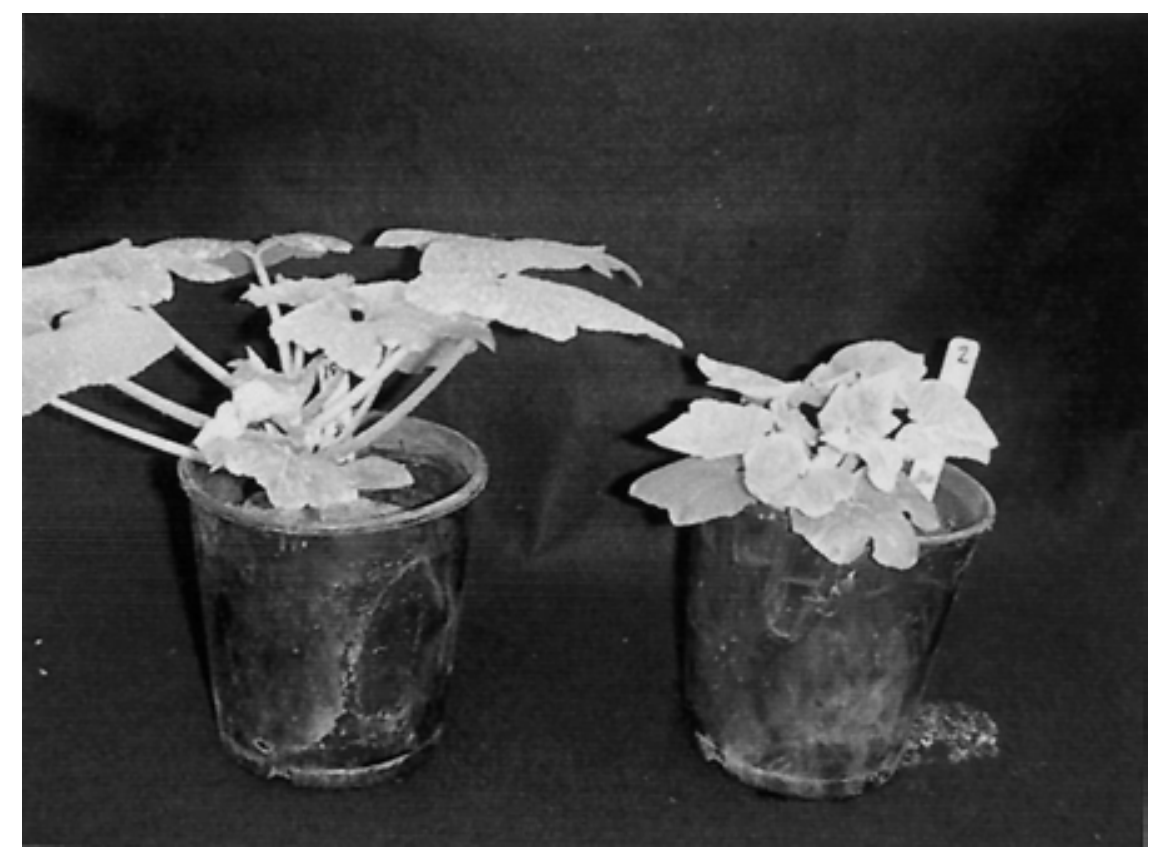

Fig. 4. Symptoms of cucurbit yellow vine disease (CYVD) on puncture-inoculated squash plant (right) illustrating severe stunting under greenhouse conditions 28 days after inoculation with WO1A of Serratia marcescens. Plants inoculated $\left(1 \times 10^{10} \mathrm{CFU}\right)$ at first true-leaf stage (11 days after planting) using puncture inoculation. Plant at left is healthy control.

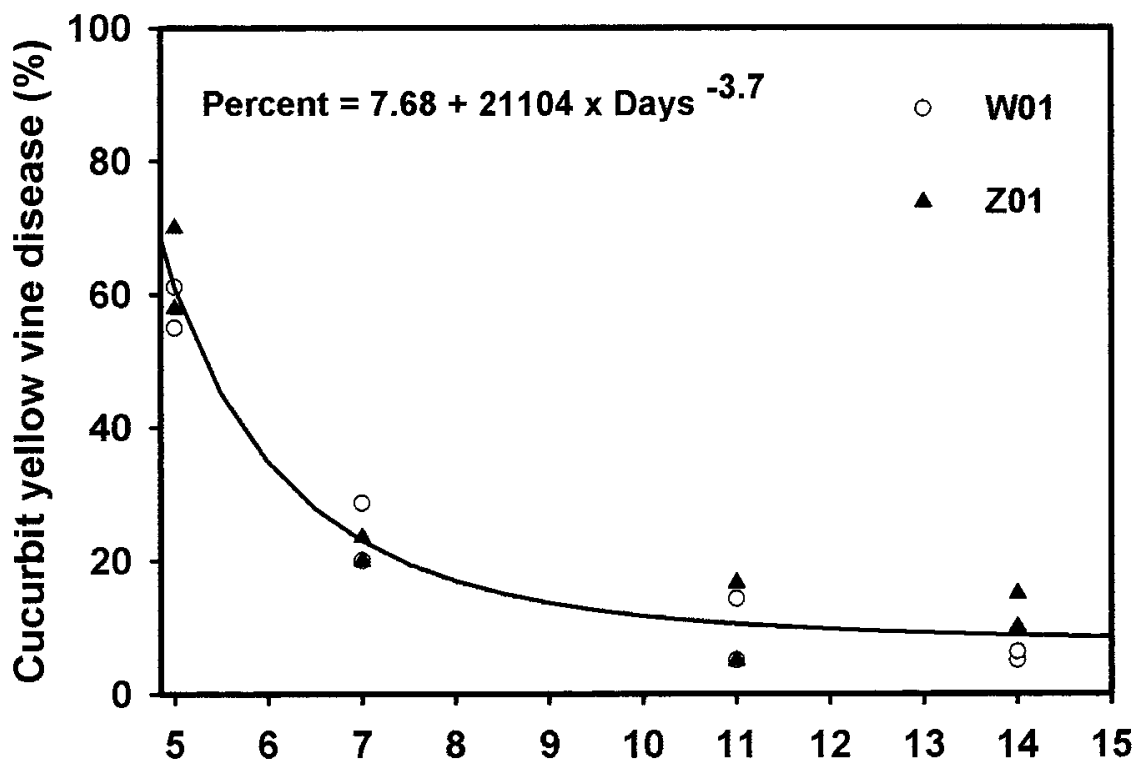

\section{Days after planting at which plants were inoculated}

Fig. 5. Percentage of squash plants exhibiting cucurbit yellow vine disease (CYVD) symptoms inoculated with CYVD strains WO1 or ZO1 of Serratia marcescens $\left(1 \times 10^{10} \mathrm{CFU}\right) 5$ days after planting (DAP) or nonexpanded cotyledon stage, 7 DAP or expanded cotyledon stage, 11 DAP or first true-leaf stage, and 14 DAP or the third true-leaf stage. Data points represent the means of 20 observations. 
buffer exhibited any abnormal symptoms. However, 26.3 and $18.4 \%$ of the positive control plants inoculated with WO1-A or Z01-A, respectively, exhibited stunting, slight foliar yellowing, and phloem discoloration. These data indicate that the production of CYVD-like symptoms requires the presence of the specific bacterial species, $S$. marcescens, and is not a result of simply overwhelming the plant tissue with a high concentration of bacteria of any species. Bacterial isolation at the second and third internode demonstrated that WO1-A and ZO1-A were present in all symptomatic plants and that they translocated systemically in the plant. In contrast, $S$. marcescens was not isolated from inoculated but asymptomatic plants and none of the non-S. marcescens bacteria were recovered from inoculated plants. Furthermore, there did not appear to be any type of hypersensitive response at the inocula- tion site using any of the test bacteria including WO1-A and ZO1-A.

Squash bug inoculations of field plants. Plants in two of the four mesh enclosures exposed to $S$. marcescens-fed squash bugs developed symptoms of CYVD, which included phloem discoloration, foliar yellowing, wilting, and plant collapse. In one of the four replications, $29 \%$ (two of seven) of the plants developed symptoms of CYVD, and in another replication, 22\% (two of nine) of the plants were symptomatic (Table 2). Both phloem discoloration and PCR analysis revealed two additional $S$. marcescens-infected plants, which lacked foliar symptoms (presymptomatic), from these same two enclosures. Plants enclosed with LB-fed squash bugs or without insects exhibited no disease symptoms, and all such plants were negative for phloem discoloration and PCR. All noncovered plants $(n=120)$

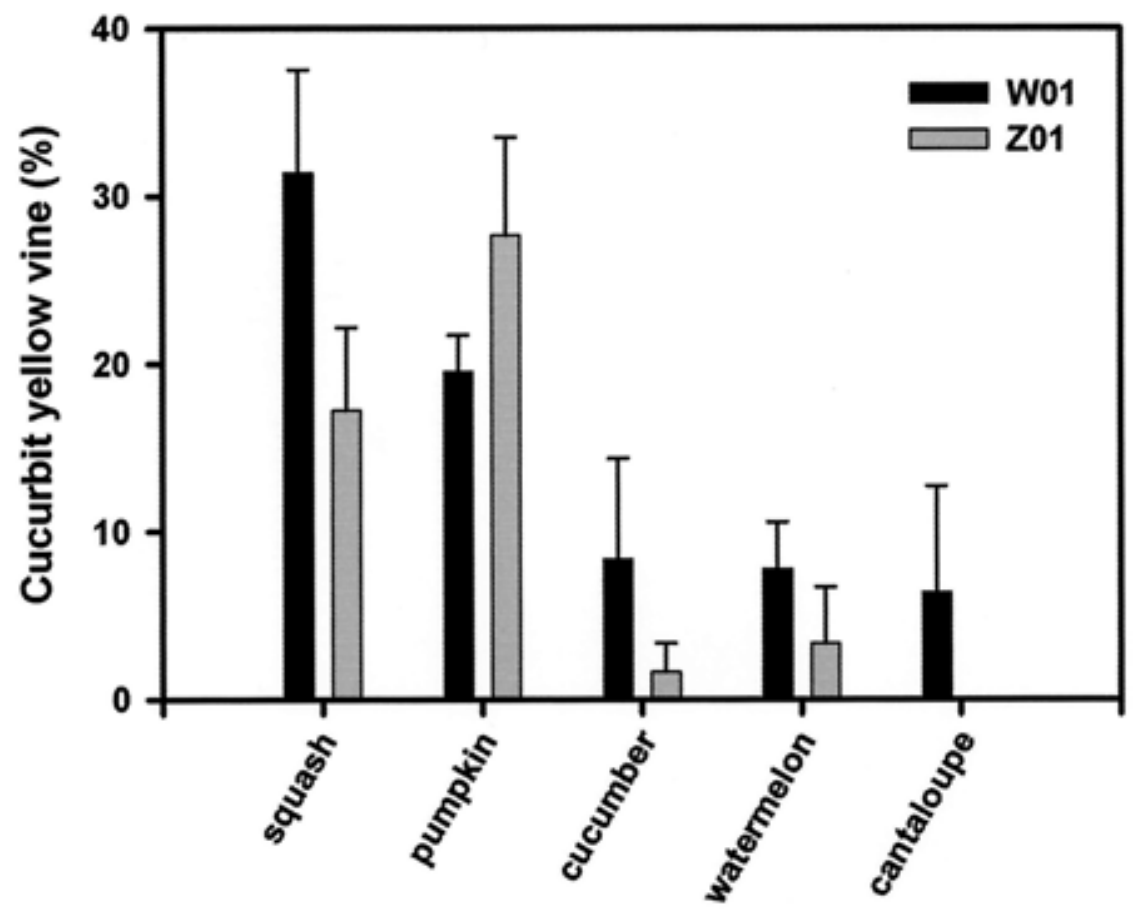

Cucurbit

Fig. 6. Percentage cucurbit yellow vine disease (CYVD) in selected cucurbits inoculated with CYVD strains WO1-A or ZO1-A of Serratia marcescens. Plants inoculated $\left(1 \times 10^{10} \mathrm{CFU}\right)$ at the expanded cotyledon stage (7 days after planting) using puncture inoculation. Bars represent the means of 40 observations and error bars represent standard error of the mean. within the experimental plot lacked foliar symptoms and were negative for phloem discoloration and PCR. Bacteria were cultured from every CYVD-symptomatic plant and shown by PCR to be indistinguishable from the inoculum strain. Attempts to isolate the bacterium from asymptomatic plants were unsuccessful.

\section{DISCUSSION}

Koch's postulates were completed for CYVD, demonstrating that a strain of the cosmopolitan bacterium $S$. marcescens is the causal agent. Although $S$. marcescens is readily cultivated from various ecological niches, its cultivation from CYVD-affected cucurbits is significant because it represents the first successful growth of a phloem-colonizing bacterium on common laboratory media (11). Using the punctureinoculation method, inoculum levels at $1 \times$ $10^{6} \mathrm{CFU} / \mathrm{ml}$ yielded no infection or disease development in inoculated squash plants. Previous studies had shown that approximately $1 \%$ infection and disease development could be achieved by syringe inoculation of squash cotyledons using CFU ranging from $1 \times 10^{6}$ to $1 \times 10^{10}$ and that inoculum concentration did not seem to matter (unpublished data). In contrast, puncture inoculations at CFU of $1 \times 10^{10}$ bacteria/ml, used in the present study, resulted in 30 to $50 \%$ disease incidence in squash plants. Although this concentration is higher than that normally used in pathogenicity studies, bacteria (four gram negative and one gram positive), shown by PCR and FAME not to be $S$. marcescens, produced no adverse effects on the test plants at this inoculum concentration. Consequently, the observed phloem discoloration was not the result of overwhelming inoculum of either $S$. marcescens or non-S. marcescens bacteria, especially in light of the fact that we achieved only about $50 \%$ disease incidence when using $S$. marcescens. Furthermore, the actual amount of inoculum that was introduced successfully into the phloem sieve cells during puncture inoculation is unknown and would be difficult to quantify.

S. marcescens strains occupy a number of different plant-associated niches, including roots and stems of rice (15) and cotton (33), although these associations

Table 2. Incidence of cucurbit yellow vine disease (CYVD) in squash plants confined with Serratia marcescens-exposed Anasa tristis

\begin{tabular}{|c|c|c|c|c|c|}
\hline Plants $^{a}$ & Symptomatic/total ${ }^{\text {b }}$ & Total plants & $\begin{array}{l}\text { Plants with foliar } \\
\text { symptoms }(\%)^{\mathbf{c}}\end{array}$ & $\begin{array}{l}\text { Plants with phloem } \\
\text { discolor }(\%)\end{array}$ & $\begin{array}{l}\text { Plants that were } \\
\text { PCR positive }(\%)^{d}\end{array}$ \\
\hline Plants unexposed to A. tristis & $0 / 4$ & 27 & 0 & 0 & 0 \\
\hline Plants exposed to broth-fed $A$. tristis & $0 / 4$ & 26 & 0 & 0 & 0 \\
\hline Plants exposed to Sm-fed A. tristis & $2 / 4$ & 35 & 11.7 & 17.1 & 17.1 \\
\hline Indicator plants & $\mathrm{NA}^{\mathrm{e}}$ & 120 & 0 & 0 & 0 \\
\hline
\end{tabular}

${ }^{a}$ Sm-fed denotes $S$. marcescens-fed squash bugs.

${ }^{\mathrm{b}}$ Number of enclosures with symptomatic plants per total enclosures.

${ }^{\mathrm{c}}$ Plants exhibited partial to full symptoms of CYVD which include phloem discoloration, stunting, plant yellowing, and plant collapse.

${ }^{\mathrm{d}} \mathrm{PCR}=$ polymerase chain reaction.

${ }^{\mathrm{e}} \mathrm{NA}=$ uncovered squash plants distributed throughout experimental plot to assess natural CYVD incidence. 
were not reported to be pathogenic to the plant host. The bacterium also has been reported as an effective biocontrol agent and plant growth-promoting rhizobacterium $(14,31,33)$. In addition, $S$. marcescens has been associated with a pathogen complex causing crown rots of alfalfa $(18,32)$ and sainfoin (Onobrychis vicifolia) (29). The habitats of $S$. marcescens extend beyond the plant environment, with these bacteria inhabiting bodies of water, soil, and animals. Several strains cause disease in insects (30) or are nosocomial pathogens of humans (16). However, yellow vine strains W01-A and Z01-A of S. marcescens differ in several physiological attributes from other $S$. marcescens strains originating from noncucurbit plants or other ecological niches (27). The type strain of $S$. marcescens is a gram-negative, motile, facultatively anaerobic, nonspore-forming bacillus in the family Enterobacteriaceae (16). Although many strains of $S$. marcescens produce the red pigment prodigiosin, none of the cucurbit yellow vine strains cultured to date produce the pigment under our growing conditions (unpublished data). Furthermore, we failed to observe bacterial motility of CYVD strains during microscopic examination.

The development of an effective mechanical inoculation method for $S$. marcescens and cucurbits was an essential step in this work. Other inoculation methods such as soil drench, syringe inoculation into the stem or cotyledon, and seed inoculation were unsatisfactory (unpublished data). Syringe inoculation resulted in the development of CYVD symptoms in about $1 \%$ of the plants inoculated, regardless of concentration. Infection rate, using the puncture-inoculation method, was highly dependent on plant growth stage when inoculated. To achieve maximum disease incidence, plants should be artificially inoculated when the seedlings first emerge and prior to cotyledons unfolding. Infection percentage dropped almost $50 \%$ when the seedlings were inoculated at the expanded cotyledon stage, which may be a difference in age of only 2 days. Using the puncture-inoculation method, the host range study showed a relative cucurbit susceptibility ranking for greenhouse-inoculated plants that differed slightly from their observed susceptibility under field conditions. For example, based on observations over several years in production areas where the disease incidence in squash may approach $100 \%$, we would expect to see about $60 \%$ incidence in watermelon and $30 \%$ incidence in cantaloupe. However, we have observed many watermelon fields and a few cantaloupe fields with $100 \%$ CYVD incidence. The fact that cucumber is the least-preferred cucurbit host for squash bug (4) may account for the fact that CYVD never has been observed in cucumber under field conditions (7). In fact, cucumber, watermelon, and cantaloupe all appeared to be about equally susceptible $(<10 \%$ incidence $)$ in the present study. Such differences between field and greenhouse results may reflect bacterial strain differences, the influence of inoculation method (fork puncture versus insect inoculation) on plant infection, or the feeding preferences of insect vectors.

Full foliar symptoms of yellow vine disease include leaf yellowing followed by partial to complete plant collapse over several days. In our greenhouse studies, we observed severe stunting, leaf yellowing, and phloem discoloration in the crown, but not plant collapse. Historically, cucurbit vine declines, caused by various soilborne pathogens, have been difficult or impossible to fully reproduce under greenhouse conditions (10). Plants maintained in the greenhouse are not subjected to the same environmental and physiological pressures (fruit load, water and temperature stress, and aggregative squash bug feeding) as those growing in the field.

In the field experiment, plants exposed to healthy, colony-bred $A$. tristis adults fed artificially on ZO1-A developed symptoms of CYVD, whereas plants exposed to control insects did not. Most of the infected plants displayed the full CYVD symptom syndrome, including complete collapse of the plant. Bacteria re-isolated from the crowns of CYVD-symptomatic plants were PCR positive and several selected samples were identified by sequence analysis of their $16 \mathrm{~S}$ and groE gene sequences (27) and rep-PCR and DNA-DNA hybridization (35) as S. marcescens. Thus, we conclude that the agent responsible for the field symptoms associated with cucurbit yellow vine disease is the bacterium $S$. marcescens.

Evidence presented from our field studies confirms that the squash bug can transmit $S$. marcescens, the CYVD causal bacterium. The $S$. marcescens $-A$. tristis relationship described here is, to our knowledge, the first instance in which the squash bug has been identified as a vector of a plant pathogen. Squash bugs, considered primary pests in squash and pumpkin, have decreasing preference for, and decreasing reproduction rates on watermelon, cantaloupe, and cucumber (3). However, the insect pest has provoked increasing concern in recent years for watermelon and cantaloupe producers in Texas and Oklahoma. Early-season commercial summer squash production is limited in Oklahoma and central Texas; therefore, there may be a selection pressure for squash bug feeding on early-planted watermelon. Margolies et al. (19) noted that squash bugs can overcome the antibiosis effects of host plant resistance within five generations. The lack of natural CYVD infection in the noncovered plants in the field experiment was not a concern because of the late-season planting date (4 August) of this experiment. Although Bextine et al. (2) reported mean CYVD incidence of 25 and $20 \%$ in noncovered squash planted in Stillwater, OK on 24 May and 15 July, respectively, watermelons planted after about 15 June typically exhibit little or no CYVD $(7,9)$. Late-planted squash and pumpkin tend to have greatly reduced incidence of CYVD and, in some years, may escape the disease altogether.

Squash bug populations in both the $S$. marcescens-fed and LB medium-fed enclosures increased during the period of the field experiment, primarily due to nymphs hatching from eggs oviposited by released adults. Extensive squash bug feeding on cucurbits may cause vascular blockage and subsequent plant wilting, a condition known as Anasa wilt (22). However, squash bug populations in our experimental field enclosures were insufficient to attribute plant collapse to A. tristis feeding alone. Also, wilt or plant collapse was not observed in enclosures containing LB-fed insects and their second-generation offspring.

Our findings demonstrate the pathogenicity of the bacterium $S$. marcescens in cucurbit yellow vine disease and also show, for the first time, the vector status of the squash bug, A. tristis. Work in progress will help to elucidate pathogenicity and transmission mechanisms in this novel plant-bacterium-insect interaction.

\section{ACKNOWLEDGMENTS}

We thank D. Baze, A. Dillard, R. Marble, and B. Anderson for their technical assistance; R. Louie and M. G. Redinbaugh for kindly providing puncture-inoculation forks; J. Edelson for providing the squash bugs used in the study; and A. Davis, J. Damicone, and J. Edelson for their thoughtful reviews.

\section{LITERATURE CITED}

1. Avila, F. J., Bruton, B. D., Fletcher, J., Sherwood, J. L., Pair, S. D., and Melcher, U. 1998. Polymerase chain reaction detection and phylogenetic characterization of an agent associated with yellow vine disease of cucurbits. Phytopathology 88:428-436.

2. Bextine, B., Wayadande, A., Bruton, B. D. Pair, S. D., Mitchell, F., and Fletcher, J. 2001 Effect of insect exclusion on the occurrence of yellow vine disease and of the associated bacterium in squash. Plant Dis. 85: 875-878.

3. Bonjour, E. L., and Fargo, W. S. 1989. Host effects on the survival and development of Anasa tristis (Heteroptera: Coreidae). Environ. Entomol. 18:1083-1085.

4. Bonjour, E. L., Fargo, W. S., and Rensner, P. E. 1990. Ovipositional preference of squash bugs (Heteroptera: Coreidae) among cucurbits in Oklahoma. J. Econ. Entomol. 83:943-947.

5. Bost, S. C., Mitchell, F. Melcher, U., Pair, S. D., Fletcher, J., Wayadande, A., and Bruton, B. D. 1999. Yellow vine of watermelon and pumpkin in Tennessee. Plant Dis. 83:587.

6. Bruton, B. D., Brady, J., Mitchell, F., Bextine, B., Wayadande, A., Pair, S., Fletcher, J., and Melcher, U. 2001. Yellow vine of cucurbits: Pathogenicity of Serratia marcescens and transmission by Anasa tristis. (Abstr.) Phytopathology 91:S11.

7. Bruton, B. D., Fletcher, J., Pair, S. D., Shaw, M. E., and Sittertz-Bhatkar, H. 1998. The association of a phloem-limited bacterium with yellow vine disease in cucurbits. Plant 
Dis. 82:512-520.

8. Bruton, B. D., Pair, S. D., Popham, T. W., and Cartwright, B. O. 1995. Occurrence of yellow vine, a new disease of squash and pumpkin, in relation to insect pests, mulches, and soil fumigation. Subtrop. Plant Sci. 47:53-58.

9. Bruton, B. D., Pair, S. D., and Wann, E. V. 1995. Yellow vine disease of watermelon and cantaloupe in Central Texas and Oklahoma. Pages 151-159 in: Cucurbitaceae '94. G. E. Lester and J. R. Dunlap, eds. Gateway Printing, Edinburg, TX.

10. Bruton, B. D., Russo, V. M., Garcia-Jimenez, J., and Miller, M. E. 1998. Carbohydrate partitioning, cultural practices, and vine decline diseases of cucurbits. Pages 189-200 in: Cucurbitaceae '98. J. McCreight, ed. ASHS Press, Alexandria, VA

11. Davis, M. J. 2001. Fastidious phloem-limited bacteria. Pages 275-282 in: Laboratory Manual for the Identification of Plant Pathogenic Bacteria, 3rd ed. N. W. Shad, J. B. Jones, and W. Chun, eds. American Phytopathological Society Press, St. Paul, MN.

12. Duthie, J. A., Bruton, B. D., and Pair, S. D. 1993. Abundance and spatial aggregation of yellow vine in crops of watermelon and muskmelon. (Abstr.) Phytopathology 83:465.

13. Edelson, J. V., Peters, M., Sutherland, A., Duthie, J., and Roberts, W. 1999. Control of squash bug in a commercial watermelon field, 1998. Arthropod Manage. Test E104.

14. Enebak, S. A., Wei, G., and Kloepper, J. W. 1998. Effects of plant growth-promoting rhizobacteria on loblolly and slash pine seedlings. For. Sci. 44:139-144.

15. Gyaneshwar, P., James, E. K., Natarajan, M., Reddy, P. M., Reinhold-Hurek, B., and Ladha, J. K. 2001. Endophytic colonization of rice by a diazotrophic strain of Serratia marcescens. J. Bacteriol. 183:2634-2645.

16. Hejazi, A., and Falkiner, F. R. 1997. Serratia marcescens. J. Med. Microbiol. 46:903-912.

17. Louie, R. 1995. Vascular puncture of maize kernels for the mechanical transmission of maize white line mosaic virus and other vi- ruses of maize. Phytopathology 85:139-143.

18. Lukezic, F. L., Hildebrandt, D. C., Schroth, M. N., and Schinde, P. A. 1982. Association of Serratia marcescens with crown rot of alfalfa in Pennsylvania. Phytopathology 72:714-718.

19. Margolies, D. C., Nechols, J. R., and Vogt, E. A. 1998. Rapid adaptation of squash bug, Anasa tristis, populations to a resistant cucurbit cultivar. Entomol. Exp. Appl. 89:65-70.

20. Melcher, U., Mitchell, F., Pair, S., Fletcher, J., and Bruton, B. 1999. New primer sets distinguish the cucurbit yellow vine bacterium from an insect endosymbiont. (Abstr.) Phytopathology 89:S95.

21. Mitchell, P. L. 2000. Leaf-footed Bugs (Coreidae) Pages 343-346 in: Heteroptera of Economic Importance C. W. Schaefer and Antonio R. Panizzi, eds. CRC Press, New York.

22. Neal, J. J. 1993. Xylem transport interruption by Anasa tristis feeding causes Cucurbita pepo to wilt. Entomol. Exp. Appl. 69:195200.

23. Pair, S. D. 1994. Potential early-season control strategies for cucumber beetle and squash bug in cucurbits. Pages 119-123 in: Proc. 13th Annu. Hortic. Ind. Conf. B. D. McCraw, ed. Oklahoma State University, Stillwater.

24. Pair, S. D. 1997. Evaluation of systemically treated squash trap plants and attracticidal baits for early-season control of striped and spotted cucumber beetles (Coleoptera: Chrysomelidae) and squash bug (Hemiptera: Coreidae) in cucurbit crops. J. Econ. Entomol. 90:1307-1314.

25. Pair, S. D., Bruton, B. D., Cartwright, B., and Duthie, J. 1993. Status of search for insect vectors of yellow vine in cucurbits. Proc. 12th. Annu. Hortic. Ind. Conf. 12:149-151.

26. Pair, S. D., Bruton, B. D., Mitchell, F., and Fletcher, J. 2000. Yellow vine management. Pages 145-148 in: Proc. 19th Annu. Hortic. Ind. Conf. J. Motes, ed. Oklahoma State University, Stillwater.
27. Rascoe, J., Berg, M., Melcher, U., Mitchell, F., Bruton, B. D., Pair, S. D., and Fletcher, J Identification, phylogenetic analysis, and biological characterization of Serratia marcescens strains causing cucurbit yellow vine disease. Phytopathology. In press.

28. Riley, D. L., Edelson, J. V., Miller, M. Cuperus, G., Roberts, B. W., Anciso, J., and Roe, N. 1998. Integrated pest management for cucurbit crops in the south central U.S. pest status, attitude toward IPM and a plan for implementation. J. Ext. 36:4 Feature 3340-3343.

29. Sears, R. G., Ditterline, R. L., and Mathre, D. E. 1975. Crown and root rotting organisms affecting sainfoin (Onobrychis vicifolia) in Montana. Plant Dis. Rep. 59:423-426.

30. Sikorowski, P. P., Lawrence, A. M., and Inglis G. D. 2001. Effects of Serratia marcescens on rearing of the tobacco budworm (Lepidoptera: Noctuidae). Am. Entomol. 47:51-60.

31. Someya, N., and Kataoka, N. 2000. Biological control of cyclamen soilborne diseases by Serratia marcescens strain B2. Plant Dis. 84:334-340.

32. Turner, V., and Van Alfen, N. K. 1983. Crown rot of alfalfa in Utah. Phytopathology 73:1333-1337.

33. Wei, G., Kloepper, J. W., and Tuzun, S. 1996. Induced systemic resistance to cucumber diseases and increased plant growth by plant growth-promoting rhizobacteria under field conditions. Phytopathology 86:221-224.

34. Wick, R. L., Lerner, J., Pair, S. D., Fletcher, J., Melcher, U., Mitchell, F., and Bruton, B. D. 2001. Detection of yellow vine in squash and pumpkin in Massachusetts. Plant Dis. 85:1031.

35. Zhang, Q., Weyant, R., Steigerwalt, A. G. White, L. A., Melcher, U., Bruton, B. D., Pair, S. D., Mitchell, F., and Fletcher, J. Genotyping of Serratia marcescens strains associated with cucurbit yellow vine disease by repetitive elements-based polymerase chain reaction and DNA-DNA hybridization. Phytopathology. In press. 